FedUni ResearchOnline

http://researchonline.federation.edu.au

This is a Submitted Manuscript of an article published by Taylor \& Francis in Research in Post-Compulsory Education on 17/04/2014, available online:

http://doi.org/10.1080/13596748.2014.897517 


\section{Credit transfer from VET to Higher Education: A pathways policy meets a roadblock}

Erica Smith and Ros Brennan Kemmis

School of Education and Arts, University of Ballarat, Ballarat, Australia; Research Institute in Professional Practice, Learning and Education (RIPPLE), Charles Sturt University, Wagga, Australia 


\title{
Credit transfer from VET to Higher Education: A pathways policy meets a roadblock
}

Keywords (any number) Credit transfer; articulation; VET; Higher Education; government policy; education pathways; widening participation

\begin{abstract}
Higher education is increasingly available to a wider range of people, not just recent school-leavers with established academic ability. One way of encouraging this trend is to provide credit transfer into higher education (HE) qualifications for people's prior vocational education and training (VET) studies. However, it is generally recognised that while a range of pathways have been created, the numbers of students involved in such pathways is relatively limited. This paper explores some of the reasons why this might be so, using, as a case study, an analysis of a national Australian government policy initiative. The initiative, known as 'VET FEE-HELP', involved the introduction of student loans for fees for higher-level VET studies and was designed partly to encourage credit transfer. Availability of loans to students was on the proviso that the course in which the student enrolled had a documented pathway providing credit transfer into a higher education course. This created a climate in which VET providers actively pursued partnerships with higher education. But recently, the credit transfer requirement of the policy has been removed. The paper concludes by discussing the issues for governments in finding appropriate policy levers to increase proportions of students transferring from VET to higher education.
\end{abstract}

\section{Introduction}

Many governments are currently trying to expand participation in higher education, and one way to do this is to encourage closer linkages between the vocational education and training (VET) system and higher education. A range of different policy initiatives have been utilised for this purpose. This paper, in a policy case study, reports on an Australian initiative, the introduction of 'VET FEE-HELP'. VET FEE-HELP involved the introduction of student loans for fees for higher-level VET studies, but the availability of loans to students was on the proviso that the course in which the student enrolled had a documented pathway providing credit transfer into a higher education course. It was thus an example of a national policy designed to 'kill two birds with one stone'. While attempting to encourage more students into higher-level VET qualifications, it also 
attempted to encourage more students to articulate into higher education qualifications. In one sense these were part of the same overarching policy objectives - to increase the number of Australians with higher-level qualifications - yet in another sense there was some inconsistency in these twin objectives, because the requirement for a credit transfer arrangement potentially limited the number of courses that were eligible. In effect the policy instrument was the use of a student-loan funding lever to encourage VET providers to negotiate credit transfer arrangements with higher education. The paper describes the initiative and its implementation, drawing on a number of sources of data including interviews with VET providers prior to the implementation of the policy. It goes on to describe the eventual outcome of the policy and explains why this particular policy lever for credit transfer failed.

\section{Context}

In Australia, higher education is provided by 39 universities and around 150 private higher education providers (known as HEPs) (Cass 2011). The teaching purpose of these institutions is to provide students with qualifications from associate degree level through to doctorates. VET is provided by 61 TAFE Institutes (TAFE is the public provider), and around 5000 private providers, collectively known as Registered Training Organisations or RTOs (www.training.com.au). Universities and TAFE Institutes offer courses across a broad range of disciplines, while private higher education and VET providers alike are often in niche markets.

VET providers mainly teach qualifications from Certificate I through to Advanced Diploma level; these form levels 1 to 6 on the Australian Qualifications Framework (AQF), which spans levels 1 to 10 (AQF Council 2011). There is a proportion of cross-over between the sectors, mainly at Diploma and Advanced Diploma (AQF levels 5 and 6) level, as these two 
qualifications can be delivered either in VET or in higher education. VET in Australia is competency-based, with most qualifications being drawn from national Training Packages. The 80 Training Packages are assembled on an industry basis and contain a range of qualifications, each consisting of a number of units of competency which are also included in the Packages (Smith 2010). While competency-based training continues to be critiqued (as summarised by Smith 2010) it is firmly embedded in the Australian VET system

Some institutions, both in the public and private sectors, are what are known as 'dual sector', being registered to deliver both VET and higher education qualifications. Several of the universities in Victoria, for example, incorporate TAFE Institutes. In addition, some other institutions operate primarily in one sector, but in a minor way in the other sector (Wheelahan et al. 2009). Some private providers in both sectors have access to government-funded places, although more often than not, learners in private providers are required to pay fees. It is a complex environment and its complexity is typically underestimated in scholarly literature, not only in Australia (Tight 2011).

As mentioned in the introduction, many countries are trying to improve student pathways within and between post-compulsory sectors. Australian government rhetoric has advocated 'seamless movement' between the vocational and higher education sectors for nearly thirty years (Smith, 2013). A current target of the Council of Australian Governments (a peak body of State and Territory premiers) is to double the proportion of Australians with higher level qualifications by 2020. There are several ways in which Australian students may proceed from the VET sector to the higher education sector. The term 'credit transfer' usually refers to credit given by the receiving higher education institution for sections of a particular course offered by the sending VET institution; while articulation refers to recognition of the whole 
course from the sending VET institution by the receiving higher education institution, and is usually expressed in terms of being exempted, for example, from the first year of study (PhilippsKPA 2007). Students may also receive individually-negotiated credit based either on previous study or on experience. Moreover, it should not be forgotten, but is often overlooked (Brennan Kemmis and Smith 2004), that VET qualifications can be utilised to allow entry into higher education qualifications, a valuable provision even if no credit is granted. This provision means that people who did not achieve academically while at school can still enter higher education later on.

In the government policy initiative discussed in the current paper, the term 'credit transfer' was used in all official documents, although in fact the clear intent related to 'articulation', since the negotiation of pathways depended on the students having completed the full VET qualification.

\section{Literature}

As noted in the introduction, the 'principle of pathways' for movement between the post-compulsory education sectors is widely accepted. Such pathways have many advantages: they help facilitate lifelong learning, they provide an alternative route into higher education particularly for people of low socio-economic status, and they avoid duplication of delivery costs and effort across the sectors (Keating 2006, 66). However, it is recognised that the implementation of pathways between the sectors is less than satisfactory; it has been said 'there are many pathways but few pedestrians' (Marron 2011). In late 2008 a review of Australian higher education (Bradley et al. 2008) ranged across a number of issues relating to the interface between VET and higher education, including this problem. The review has been influential in a number of current Australian developments, leading to a new use of the term 'tertiary sector', the term taken to mean that there should be greater integration between VET 
and higher education. This has increased pressure to improve pathways between VET and HE.

While desirable in theory, increasing articulation from VET to higher education also has many challenges. For students, as Watson (2007) points out, the provision of too much credit can be problematic; the common practice of providing a full year's credit to students moving from VET means that they may begin to study alongside second-year students who have had the advantage of familiarisation with the university environment and academic practices. Knox (2005) suggests that such students require additional, formal, curriculum support as well as ongoing support in the development of academic skills. The differences in pedagogical approaches between VET and higher education, particularly in countries where VET is competency-based is considerable and leads to different conceptions of learning among students who have previously studied in VET and those who have not (Smith and Blake 2009).

Reasons why pathways may succeed or fail are the subject of a great deal of literature, particularly in Australia. An Australian government-commissioned report identified the most important enablers of credit transfer from VET to HE (PhilippsKPA 2007, 8-11). These were identified as leadership, systems, mutual respect and commitment, information provision, and transition support. Three potential enablers were also described: industry involvement, geographic proximity, and the presence of student demand for the pathway. A number of impediments were also identified in the report. At system and institutional levels these were: sectoral differences in funding and accountability, attitudes and cultures in the respective institutions and administrative issues; at curriculum level, impediments were curriculum and qualification design differences as well as issues relating to assessment, because much VET assessment is ungraded (PhilippsKPA 2007, 11-14). Differences in status between the sectors (as noted by Keating 2006, 66) are implied by PhilippsKPA's 'mutual respect and 
commitment' although, as the report states 'mutual respect cannot be mandated' (PhilippsKPA, 2007, 12); the report referred to cultural differences and attitudes held by personnel in both sectors and in government agencies. On a more practical note, the report mentioned a lack of resources in both sectors to pursue major pathway initiatives.

As the PhillipsKPA report was commissioned by the government department responsible for VET FEE-HELP, it might be expected that the report had some effect upon policy formulation. Presumably, the intent of the credit transfer provision of the student loans policy was to provide an additional, and powerful, enabler to add to those three already identified.

\section{Method}

The VET FEE-HELP scheme, introduced in 2007 and implemented from 2008, is described and analysed in this paper as a case study of a nation's policy initiative designed to improve movement from VET to higher education. The authors were involved, in a minor way, in the implementation of this policy. They were invited by the Australian peak body of private providers of VET and higher education, the Australian Council of Private Education and Training (ACPET), to provide a series of professional development workshops for its members in six capital cities in 2007 on the initiative, focusing on the credit transfer provision included in the legislation, and as background to this work were invited to national planning meetings of government department staff and stakeholders. The government department was known at that time as the Department of Education, Science and Training.

Multiple data sources are utilised in this paper. To help prepare for the workshops, interviews were undertaken with Chief Executive Officers of five private Registered Training Organisations (RTOs), and senior staff in two universities (one vice-chancellor and one deputy vice-chancellor (academic) about their pathways practices at that time. The names of suitable 
RTOs were supplied by ACPET. The RTO managers were asked the following questions:

- What courses do you offer at Diploma and Advanced Diploma level and how they are delivered?

- Do you have existing credit transfer arrangements with higher education providers?

- What did you think about the Budget announcement about FEE-HELP?

- As an RTO, what do you need to know about credit transfer to universities?

- What would you like to be included in the workshop?

- What do we need to know so that we can make the workshops more useful?

The senior university staff were asked about current pathway arrangements and associated enablers and barriers. They were also asked what information they would like RTOs seeking credit transfer to provide to them.

In addition, data from an ACPET survey of providers about VET FEE-HELP were provided and analysed. Notes were taken of issues raised at the planning meetings attended by the authors with the government department responsible for introducing and managing VET FEEHELP, the Department of Education, Science and Training, as the policy and procedures were progressively developed. Notes were also taken of issues raised at the ACPET workshops, and workshop evaluation forms were analysed. Research ethics committee permission was gained for data from these activities, as well as the interview data, to be used in publication.

In this paper, the progress of the initiative since its implementation in 2008 is described through data provided in a seminar given by the relevant senior government official four years after the initial research, and through the release of government policy documents in mid-2012.

The initiative is used as a case study of an attempt, through policy, to encourage a desired behaviour - in this case, increased credit transfer from VET to higher education - at the same time as its major intent, which was to increase participation in VET-sector diplomas and advanced diplomas through a student-loan system. 


\section{VET FEE-HELP case study findings}

\section{Introduction of the policy initiative}

In Australia, as in many other countries, students in higher education pay a contribution towards the cost of their education. This was originally known as the Higher Education Contribution Scheme (HECS), and involves the student incurring a debt to the government, with the government forwarding the HECS contribution to the university on behalf of the student. Students have the choice of paying the contribution 'upfront' each semester, at a discounted rate, or having the debt paid off through the national taxation system once they attain a certain income level. The HECS scheme was subsequently expanded to allow for full fee paying university courses to be treated in the same way, and became known as 'HECSHELP' while the scheme for fee-paying HE courses was called 'FEE-HELP'.

Prior to the initiative described in this paper, VET students did not have access to loan assistance for their fees (Chapman, Rodriguez, and Ryan 2008). In 2008 VET FEE-HELP was introduced for higher-level VET qualifications (diplomas and advanced diplomas), but only when the VET provider had negotiated an agreed pathway providing credit transfer into a higher education qualification. The proposal was introduced in the Federal Budget in May 2007, with the following words in the Budget Statement relating to the Department of Education, Science and Training:

FEE-HELP for Vocational Diplomas and Advanced Diplomas will allow full-fee paying students to access interest free loans to meet the upfront costs of studying. This will encourage more people with existing qualifications to further build their skills and knowledge.'(Commonwealth of Australia 2007, 88)

The press release issued by the Minister, Andrew Robb, gave further information: 
FEE-HELP will be extended to full-fee-paying students in Diploma and Advanced Diploma courses that are accredited VET qualifications, where agreed credit for a university degree is available to the student. RTOs will be encouraged to seek approval from the Australian government to receive FEE-HELP for Diploma and Advanced Diploma students, if they have an agreement with a university that their students can receive appropriate credit transfer into a related degree qualification. (Andrew Robb AO, Minister for Vocational and Further Education (press release, May 2007).

It was quickly clarified that pathways could be to private HE providers as well as universities.

ACPET instituted an information and professional development campaign for its members during 2007. While some of this campaign focused on the financial and registration mechanics of the new system, an important element related to the credit transfer provision, because the requirement for pathways to HE qualifications led VET providers actively to seek partnerships with HE providers.

At the time that VET FEE-HELP was introduced, the numbers of students enrolled in VETsector Diploma and Advanced Diploma courses were not high. Total figures of 173,100 enrolled in Diploma and higher qualifications at this time constituted only $10.5 \%$ of all reported VET enrolments compared, for example, with Certificate III enrolments of 437,700, which constituted 26.7\% of enrolments (NCVER 2006). Figures obtained from the National Centre for Vocational Education Research as part of the preparation for the professional development workshops, showed that for Diplomas, Business and Management courses were by far the most popular, with around 30,000 enrolments across Australia, with Human and Welfare Studies second at just under 20,000. For Advanced Diplomas, Business and Management again led with just over 10,000 enrolments, with Banking and Finance second with around 6,000. Technical courses (electrical and engineering-related) took third, fourth and fifth place for 
Advanced Diplomas, whereas this was not the case for Diplomas. It should be noted at this point that figures on enrolments in VET courses are neither reliable nor complete, as private providers have not, to date, been required to report enrolments, unless government funding is received for those students. Therefore the figures quoted should not necessarily be regarded as complete, but rather as indicative of the fields of study involved.

\section{Providers' views}

The five RTOs whose staff were interviewed provided Diploma and Advanced Diploma qualifications in a range of industry and occupational areas including management, quality assurance, finance, security and public safety, event management, and children's services. Two RTOs were also providers of higher education. The latter RTOs reported no problems with credit transfer into their own and, in one case, others' higher education courses; but all of the other three mentioned previous failures to negotiate pathways. One said, 'I was a bit disappointed about the credit transfer rider, because of our difficulties in asking for it (credit transfer).' RTO interviewees' comments about attempts to negotiate credit transfer with universities included:

'I have been passed from pillar to post when contacting universities.'

'I approached $X$ university but the academics had no idea how to do it.'

'I tried to organise with $Y$ university, but got passed around and none of the contacts seemed to know anything.'

'I sent documents to an academic at $Z$ university, but the academic didn't get back to me.'

Respondents said that universities did not provide any documentation that outlined the processes for credit transfer or articulation, but they felt that they ought to. One said that understandings about credit transfer were very variable within universities; as were attitudes towards granting credit: 'Their (Schools’) attitude ranges from very facilitative to very 
conservative'. Three participants noted that academics 'were always too busy'; in the words of one, some staff ‘don’t want to pursue opportunities; they don’t want to do anything that might increase their workload'. Another said that 'anything under 500 students, and the universities are just not interested'.

One respondent noted some issues related to mapping curriculum content. He said, ‘Universities don’t seem to have such formal \& comprehensive documentation of curriculum as we do in the VET sector.' Furthermore, he suggested that where non-Training Package VET-sector qualifications were being discussed, universities seemed less interested, as they could not look up the content of the qualifications on the National Training Information Service, where at that time details of all Training Package qualifications could be found ${ }^{1}$. He was concerned about possible intellectual property consequences of sending learning materials to a university for inspection and mapping. It was also noted by one respondent that, although academics often raised the issue of the different pedagogy between VET and higher education, nobody seemed to offer advice on how to 'build a bridge' between the two.

Despite these negative experiences, the respondents were all enthusiastic about the possibilities opened up by VET FEE-HELP, because the availability of loans would enable more students to access their courses. A respondent from an RTO which was also a higher education provider, said that when higher education FEE-HELP became available to its higher education students,

... we saw a real lift in the quality of students. It became not just those that could afford to pay, but the best quality that applied. We expect this to happen for the VET sector. Another said, 'We just want FEE-HELP really badly, to broaden our selection of students to those who currently can’t pay.'

\footnotetext{
${ }^{1}$ This information is now found at www.training.gov.au
} 
Interviewees said that students were already actively seeking credit transfer into university. One noted that its students, who were mature adults, were often 'fearful' about study, but that once they had succeeded to Diploma or Advanced Diploma level, 'they are excited and want to go further'. Responses to a question regarding what RTOs needed to know about credit transfer to universities can be summarised as follows: knowing who to talk to within the university; knowing the process and the time frames (eg committee dates) for negotiating credit transfer at that university; and how they could get comprehensive information from universities about what was required. Each of these issues was raised by at least two of the five respondents.

The following points were raised by respondents in a question eliciting potential advice that could be offered to RTOs seeking credit transfer arrangements with higher education providers:

- Go as high within the university as possible;

- Push it through as quickly as possible in case a key staff member moves on;

- Show evidence of high quality in your courses;

- Propose 'robust and justifiable credit transfer arrangements that could be auditable'; do not go for the easiest option 'if it's not justifiable'.

The senior university staff provided an additional perspective on the issue. One was a large regional university (interviewee A) with a large proportion of distance education students. The other university (interviewee B) was a smaller dual-sector university. At that time University A provided credit transfer pathways only to students of specified VET providers. University A's interviewee (the Deputy Vice-Chancellor) felt that there were too many quality risks to offer standard pathways for qualifications from any VET provider, although he said 'I could possibly 
be persuaded that these concerns are unjustified at Diploma and Advanced Diploma level.' The university only offered pathways for completed qualifications, and sometimes required VET providers to 'fill in' missing content before students were allowed credit; this occurred, for example, in the nursing discipline. This interviewee also noted difficulties associated with differential dates for university course reviews and Training Package reviews. Interviewee B (the Vice-Chancellor) explained that his university, as a dual-sector, was looking at transfer for students from its own TAFE section as well as from other RTOs. The arrangements at university B were unusual in that standardised credit transfer was already available into 'Applied Degrees' which were offered from the TAFE section rather than the HE section of the university. Advanced Diplomas secured two years' credit into the Applied Degrees; in effect the first two years of the degree did not exist. This arrangement overcame many of the administrative and operational difficulties mentioned by University A and identified in the literature.

Both universities said that the contact person for RTOs seeking credit would normally be the Head of School at the university. Interviewee A suggested the types of data that RTOs should provide for universities when seeking credit transfer arrangements, as follows:

- Details of library faculties and of staff qualifications;

- Nature of student body;

- Evidence of discussion between the course co-coordinators at the RTO and the university; and

- Identification of any gaps between the content knowledge of the VET qualification and the part of the university course for which credit was sought.

When set alongside the list of information that RTOs said they needed, it is clear that both parties have information needs which should be communicated to each other. In the workshops for ACPET, these two sets of needs were translated into suggested templates for RTOs to use. 
The final data source for providers' views was a short 2007 survey carried out by ACPET of its members, relating to their expectations about the effects of VET FEE-HELP. Thirty three RTOs responded to the survey, of which eight were also higher education providers (HEPs). In a response to a question about potential use of the new policy, the non-HEP RTOs expected that most of their students would take advantage of VET FEE-HELP (the majority gave answers of over $80 \%$ of the students in the relevant courses). In a typical qualitative comment, one RTO said 'It is often said by students that they have to save for their next unit. I think the rate at which units are purchased and completed would increase significantly.' The effects of the opportunity provided by the new policy were expected to be significant. RTOs expected increases in enrolments varying from $10 \%$ to $200 \%$, with the majority suggesting between 50 and $100 \%$ increases. Around half indicated that they would offer additional qualifications. A concern was expressed by two RTOs that Certificate IV qualifications, even where a prerequisite for Diploma entry, were not to be covered.

\section{Policy issues}

The credit transfer proviso of the proposed new policy was controversial. Massaro (2007) in a report prepared for ACPET, had criticised the decision to link the availability of FEE-HELP to credit transfer, arguing that it was 'an unnecessary constraint on those applying for FEE-HELP status.' He argued that Diploma and Advanced Diploma courses provided graduates for jobs needed in the economy, and should not be seen as 'subsets of university degrees' (Massaro 2007, 2). He also pointed out that many qualifications did not have an obvious link to a university degree. At the Reading of the Bill in June 2007, Minister Robb highlighted several issues that had attracted public criticism; one of these was the credit transfer rider. However, the policy proceeded, through the development of an amendment to the Act which had established HECS-HELP and FEE-HELP - the Higher Education Support Amendment 
(HESA) Bill 2007.

At the meetings with staff of the government department, the authors found many of these issues discussed fully and frankly. It was clear at the meetings that the encouragement of pathways from VET to higher education qualifications was an explicit policy intention of the scheme, yet it was stated that legitimate 'terminating qualifications' - ie those where there was no suitable pathway available to higher education qualifications - were to be respected, and also that dysfunctional behaviour to meet credit arrangements would not be encouraged. The level of credit was a matter for discussion; while the Budget papers stated 'significant credit', in other places the word 'appropriate' was used by the Minister and senior bureaucrats. It was suggested that $30 \%$ credit into a degree might be consider sufficient. Government staff recognised that appropriate credit could depend on choice of electives in the VET course and that RTOs would need to make this clear in their advertising. Staff were also aware that decisions need to be made about the appropriate length of credit transfer agreements, in view of review timelines for VET-sector Training Packages. This was because Training Packages were regularly reviewed, changing the mandated content of qualifications. Staff acknowledged that RTOs would need assistance in implementing credit transfer, and suggested a range of matters that they thought should be included in the forthcoming ACPET workshop, including advice to RTOs on how to approach universities.

\section{Issues raised at workshops}

The workshops presented by the authors incorporated all points raised by the stakeholders with whom they had interacted, and included the development and provision of a suggested template for written proposals from VET providers to universities. The evaluation forms from the workshops showed that, overall, the participants most appreciated two things: advice on how to 
approach universities, and the template. Issues that were raised in discussions and questioning, and that therefore could be inferred as matters of concern to RTOs, included:

- Should RTOs approach a range of universities or confine themselves to one partner?

- What happens where there is no logical pathway from a VET qualification to a degree?

- How can Training Package reviews be accommodated?

- How can the differences between VET units of competency and HE 'learning outcomes' be accommodated?

- Do credit transfer arrangements to an overseas provider make a course eligible for VET FEE-HELP?

- 'Nested qualifications' - where Certificate IV qualifications were required to enter diploma or advanced diploma qualifications - would FEE-HELP be available for the Certificate IV qualifications?

These issues were gathered and fed back to ACPET and government staff for consideration in the final policy development stages.

Four years on - the consequences

In the latter part of 2011, the government official who was at that time in charge of VET FEEHELP made a presentation to a large audience of RTOs at the annual ACPET conference, on the current position and future outcomes of VET FEE-HELP. It was reported that by the end of 2010, the third year of operation of the scheme, 94 providers had gained VET FEE-HELP status, for 1459 eligible courses (McAuslan 2011). A reported 26,112 students had taken out a VET FEE-HELP loan; this represented a large increase from the 2009 figure of 5,262, with $25 \%$ of the increase in Management courses but otherwise a uniform increase across fields of study. The large rise from 2009 was attributed to an amendment to the HESA legislation in 
early 2009 relating to the State of Victoria only. This amendment allowed, for that State only, government-subsided courses as well as full-fee-paying courses to be eligible for VET FEEHELP, and also removed the requirement for credit transfer arrangements ${ }^{2}$. In relation to credit transfer to higher education, it was stated that pathways were still piecemeal and tended to be negotiated among individual education providers, and that 25 of the 94 providers that had registered for VET FEE-HELP were dual-sector institutions (public and private) (McAuslan 2011).

Questioning from the audience to the speaker indicated that some concerns raised originally were still current; for example, nested Certificate IV qualifications were not covered by VET FEE-HELP even though the lower-level qualifications were needed to complete the diplomalevel qualification. However the audience's comments were generally positive, with one RTO stating that the number of Australian students enrolled in diploma and advanced diploma qualifications in that RTO had trebled since the advent of VET FEE-HELP. Thus while the scheme as a whole was considered a success, the pathways objective was still contested. It was reported that there was pressure to expand the 'Victorian' relaxation nationally, although, it was stated, government officials remained committed to the credit transfer provisions (McAuslan 2011).

A review of the policy, flagged at the seminar and eagerly anticipated, was released some time later, in mid-2012, although dated September 2011 (Grosvenor Management Consulting 2011). The paper recommended removal of the credit transfer provision nationally, and also extension of the scheme to students undertaking Certificate IV level qualifications. The rationale for removing the credit transfer provision was that the removal of the provision in Victoria was seen as inequitable for students in other States and Territories (Grosvenor Management Consulting 2011, 13). Also, numbers of credit transfer students were reported to

\footnotetext{
2 The amendment was introduced by the Victorian government to address another initiative which had made access to government-funded VET places more difficult.
} 
be low (eg 424 VET FEE-HELP students from 2009 were studying at a higher education provider in 2012, and only 121 were in courses related to their VET course (Grosvenor Management Consulting 2011, 39). This criticism perhaps failed to take account of the fact that it might be expected to take some time for the 'pipeline' to produce high numbers.

\section{Discussion}

The data collection undertaken at the time of the introduction of the VET FEE-HELP policy indicates that RTOs’ primary interest was to increase the opportunity for more students to be able to access financial help to undertake their studies. RTOs would have liked to be able to provide credit transfer pathways for their students to higher education, but their previous experiences in this area indicated that on the whole they viewed this as a difficult task. To help them in this task they welcomed ideas that assisted them to communicate with universities. Their responses, in the interviews, survey and workshops, supported the analysis of 'enablers' proposed in the PhillipsKPA report (2007) and particularly the enablers of leadership and information provision. Alongside this general feeling, there was, however, a current of belief that the credit transfer requirements were unnecessary and problematic, although theoretically desirable. The policy-makers, on the other hand, viewed the requirements as important in meeting the higher education participation targets and more generally as beneficial for students to have the opportunity to progress further. The twin aims of the policy were not valued equally by all stakeholders.

The next section discusses some possible reasons why the credit transfer provision of VET FEE-HELP eventually fell, despite a continuing commitment from policy-makers in the government department. Three major national developments are described; one that made universities more nervous about pathways, and two that strengthened the imperative to increase 
Diploma and Advanced Diploma enrolments at all costs. All of these developments weakened commitment of stakeholders to the credit transfer provision.

The first development was the approval of a strengthened Australian Qualifications Framework (AQF) in 2011. While the Australian AQF had been in existence for 16 years, there was considerable variability between the levels of detail of the specifications at different qualification levels. The new document (AQF Framework Council 2011), developed after exhaustive consultation, established systematic descriptors for all qualification levels, which range from Certificate I level to $\mathrm{PhD}$; PhDs are at level $10^{3}$. By 2015, all Australian courses, whether in VET or higher education, must be compliant with the AQF, and need to, inter alia, show how they provide preparation for 'further learning' as well as for work. To underline this requirement, the AQF document incorporated a strengthened 'Pathways policy' (AQF Framework Council 2011, 75-78). This sets down more firmly than previously a requirement for education providers to provide explicit pathways into and out of qualifications, and recommends the amounts of credit to be granted. For example, it is recommended that $50 \%$ credit into a three-year bachelor degree (AQF level 7) be provided for an advanced diploma (AQF level 6). However the AQF Council did not actually mandate such credit arrangements, leaving it to the discretion of RTOs and higher education providers to make their own determinations. The strengthened qualifications framework may appear to work in favour of the VET FEE-HELP credit transfer provision, but the reality is more complex. The inclusion of the Pathways Policy within the AQF document rather than in a separate document affords it more credibility, and more likelihood of being read by relevant university staff. But the ‘regularisation' of pathways guidelines creates some difficulties. Previously, national guidelines on amounts of credit were regarded as loose guides only. The new Pathways Policy

\footnotetext{
${ }^{3}$ Full details of each qualification level are available at http://www.aqf.edu.au
} 
adopts the same recommended proportions of credit as these guidelines, but presents the appearance of being more prescriptive, and it is possible that universities could refuse pathways because they felt nervous about the amounts of credit recommended.

The second development has been the introduction of 'reforms' in a number of States, spearheaded by Victoria (Department of Innovation, Industry and Regional Development 2009), which have affected funding for VET. The Victorian provision meant that students could not access government-funded places for study in a qualification at a level which they have already attained. Thus a student who already had a degree could get a government-funded place in a diploma or advanced diploma course. This provision affected enrolments in diplomas in TAFE Institutes in Victoria, and enrolments in 'feeder' lower-level qualifications have also been affected. The HESA Act was amended in 2009, as we have seen, to remove the credit transfer requirements for Victoria, in order to address this situation of falling numbers in diploma and advanced diploma courses.

A third development, another adversely affecting numbers of enrolments in diplomas and advanced diplomas, relates to overseas students; some VET providers have specialised in offering these levels of qualification to overseas students (Smith et al. 2009). Since 2007 a number of developments have combined to depress the overseas student market (Smith and Smith 2011). Hence those providers relying on overseas markets have experienced a decrease in numbers in diploma and advanced diploma enrolments. Moreover, consistent with national, and indeed international mood to ‘tighten up’ migration, overseas students were not themselves made eligible for VET FEE-HELP.

These three developments have affected the policy environment in which the credit transfer requirement for eligibility for VET FEE-HELP had to operate. The first, while moving pathways between VET and Higher Education into a more formal domain, has, in its detail, 
created potential concerns for universities about pathways. The second and third developments affected the market for diplomas and advanced diplomas and thus provided an incentive to remove the credit transfer rider, which had always been criticised by some parties as providing a potential brake on take-up of VET FEE-HELP.

In terms of implementation at RTO level, our data showed that RTOs were primarily interested in allowing their students access to loans, with the twin and not inconsistent objectives of greater equity for their students compared with those in TAFE Institutes who could receive government-funded places, and of increasing their student numbers. Our research showed that while some RTOs saw the credit transfer provision as a difficulty, others embraced it because their students were looking for further study opportunities. Once the credit transfer provision was instituted, RTOs knew they needed to move quickly on it, otherwise, as one of our respondents put it, 'you're dead in the water'. The government-commissioned review (Grosvenor Management Consulting 2011, 48) provided some approximate data showing that, in implementation, about the same proportion of RTOs experienced difficulty satisfying the credit transfer requirement as those who found it easy or very easy.

A further difficulty, a thread weaving through the data collection and workshops, was the issue of relative esteem of the VET and higher education sectors, a perennial issue (Keating 2006). The argument was put by RTOs that if increased participation in diplomas and advanced diplomas is viewed as being valuable in itself, and if such qualifications are deemed to have appropriate employment outcomes, the availability of financial assistance to students should not be dependent on arrangements for articulation into a higher education qualification. The latter provision seems implicitly to downgrade the VET-sector qualification and created a further argument for the removal of the rider.

A discussion paper was released for consultation by the government department now responsible for VET FEE-HELP, the Department of Innovation, Industry, Research, Science 
and Tertiary Education (DIISRTE, 2012). The discussion paper, following quickly upon release of the review discussed above (Grosvenor Management Consulting, 2011) reports on an agreement reached between Federal and State/Territory governments that the credit transfer provision will be removed. This, it seems, is not in fact a matter for discussion, but merely for reporting. The arguments provided for removing the provision are those raised at the beginning of the VET FEE-HELP process and those reported during our involvement with the scheme; an added argument is that credit transfer is 'at the discretion of' the higher education provider' and thus not within the power of VET providers to effect. The discussion paper goes on to state that 'It is considered that there are more appropriate and effective platforms available to facilitate learning pathways in the tertiary sector.' (DIISRTE 2012, 9); however, it does not suggest what these might be.

\section{Conclusion}

The analysis presented in this paper is limited to some extent by the relative lack of data concerning the outcomes of the introduction of the VET FEE-HELP initiative. While detailed data is presented on the expectations of RTOs and the issues with which the government department was grappling, the evidence from 2011 is limited to two sources: a government official via a public seminar, and the commissioned review of VET FEE-HELP with its followup discussion paper. There is thus a need for further research with RTOs on their experiences of the scheme. Such research should also involve their partnering universities and private higher education providers and, importantly, the expectations and experiences of the students. A further difficulty in the analysis is that it would be impossible to estimate the effects of FEEHELP on numbers of enrolments in diplomas and advanced diplomas, because of the effects of other developments in the volatile policy environment. 
However the lack of detailed data on the outcomes does not negate some possible conclusions concerning the difficulties of incorporating two major policy objectives within one relatively small initiative, especially in an environment where other policy changes are occurring. At the time of implementation, fears were raised that the credit transfer provision of the VET FEE-HELP initiative would limit the take-up of the initiative. The three subsequent policy developments described in the discussion above, while unanticipated, served to increase the challenge for Australia of trying to maintain or increase enrolments in diploma and advanced diploma courses, and so the barriers to increased enrolments created by the credit transfer provision loomed larger in the policy eye. The credit transfer provision became seen as a roadblock to increased enrolments; the removal of this perceived roadblock had the effect that another roadblock was created, that blocked the pathways.

It is possible that in the absence of the unanticipated and relatively hostile developments in the external environment, the credit transfer requirement may have survived. It may not be a major disaster that the credit transfer requirement has fallen; it could be that the majority of students may only seek a ‘terminating qualification' at diploma or advanced diploma level. But the fact remains that no policy levers now remain to encourage movement from VET to higher education in Australia. The sectors may need to fall back upon the 'enablers' identified by PhillipsKPA (2007) and supported by the data in this paper, or students may continue to carve out pathways for themselves. But the size of the challenge associated with piecemeal arrangements that are not underpinned by any external imperative, emerged clearly from the research reported in this paper.

\section{References}


Australian National Training Authority (ANTA). 1997. A bridge to the future: Australia's national strategy for vocational education and training, 1998-2003. Brisbane: ANTA.

Australian Qualifications Framework Council (AQF Council). 2011. Australian Qualifications Framework First Edition. Adelaide: AQF Council. www.aqf.edu.au

Bradley, D., P. Noonan., H.Nugent, and B. Scales. 2008. Review of Australian Higher Education, final report. Canberra: Australian Government.

Brennan Kemmis, R and E. Smith. 2004. "Report of workshop: Implementing the Training and Assessment Training Package across the sectors.” Paper presented at the Australian Vocational Teacher Educators’ Colloquium, Melbourne, November 22-23.

Chapman, B., M. Rodrigues, and C.Ryan. 2008. “An analysis of FEE-HELP in the vocational education and training sector”. Australian Economic Review 41 (1): 1-4.

Cass, M. 2011. "Providing diverse, high quality pathways through private education \& training”. Paper presented at Defining and Achieving Interconnected Tertiary Education Conference, Crowne Promenade Hotel, Melbourne, Australia, 30-31 March.

Commonwealth of Australia. 2007. Portfolio Budget Statements 2007-8; Education, Science and Training Portfolio, Budget related paper no. 1.5. Canberra: Commonwealth of Australia.

Department of Innovation, Industry and Regional Development (DIIRD). 2009.Securing Jobs for Your Future - Skills for Victoria. Melbourne: DIIRD.

Department of Industry, Innovation, Science, Research and Tertiary Education (DIISRTE). 2012. Discussion paper: VET FEE-HELP redesign 2012. Canberra: DIISRTE. Grosvenor Management Consulting. 2011. "Post implementation review of the VET FEEHELP Assistance Scheme Final Report” Canberra. Department of Education, Employment and Workplace Relations: 
http://www.innovation.gov.au/skills/SkillsTrainingAndWorkforceDevelopment/Documen ts/Support/PIRofVFHFinalReport.pdf

Keating, J. 2006.“Post-school articulation in Australia: A case of unresolved tensions”. Journal of Further and Higher Education 30 (1): 59-74.

Knox, H. 2005."Making the transition from further to higher education: the impact of a preparatory module on retention, progression and performance”. Journal of Further and Higher Education 29 (2): 103-110.

Marron, A. 2011.“Examining the end goal of collaboration”. Paper presented at Defining and Achieving Interconnected Tertiary Education Conference, Crowne Promenade Hotel, Melbourne, Australia, 30-31 March.

Massaro Consulting. 2007.Issues impacting on the implementation of FEE-HELP for Diploma and Advanced Diploma courses offered by private providers. Melbourne: Australian Council for Private Education \& Training.

McAuslan, N. 2011.“VET FEE-HELP:Looking back, moving forward”. Paper presented at Australian Council for Private Education \& Training national conference, Brisbane: Australia, August 25-26.

NCVER. 2006. Australian vocational education and training statistics: National VET provider collection: Students by major qualification by course field of education and sex, 2005. Adelaide, Australia: NCVER.

PhillipsKPA. 2007. Giving credit where credit is due. Final report for Department of Education, Science \& Training. Byron Bay, NSW: PhillipsKPA Ltd.

Smith, E. 2013. “ ‘Qualifications for work and further learning’: The Australian approach to hybrid qualifications", in Hybrid qualifications: Structures and problems in the context of European VET policy, edited by T. Deissinger, J. Aff., A. Fuller \& C. Jorgensen. Bern, Switzerland: Peter Lang, pp 227-240. Bern, Switzerland: Peter Lang, pp 227-240. 
Smith, E. 2010.“A review of twenty years of competency-based training in the Australian vocational education and training system.” International Journal of Training \& Development 14 (1): 54-64.

Smith. E, and A. Smith. 2011. "Has Australia turned its back on international students?” . Paper presented at Creating and Sustaining International Connections: he 41st annual conference of SCUTREA, the Standing Conference on University Teaching and Research in the Education of Adults, Lancaster University, July 5-7.

Smith, P and Blake, D. 2009. “The influence of learning environment on student conceptions of learning”, Journal of vocational education and training 61 (3): 231-246.

Smith, E., R. Brennan Kemmis, L. Grace, and W, Payne. 2009.Workforce development for service industries VET practitioners. Sydney: Service Skills Australia.

Tight, M. 2011.”How many universities are there in the United Kingdom? How many should there be?” Higher Education 62 (5): 649-663.

Watson, L. 2007.”A different route.” Campus Review, September 11.

Wheelahan, L., G. Moodie. S. Billett, and A. Kelly. 2009. Higher education in TAFE. Adelaide: NCVER. 